\title{
Some Factors Affecting Production and Assay of Escherichia coli Haemolysins
}

\author{
By I. S. SNYDER AND P. ZWADYK \\ Department of Microbiology, University of Iowa, \\ Iowa City, Iowa 5224I, U.S.A. \\ (Accepted for publication 5 September 1968) \\ SUMMARY
}

The amount of haemolysin produced by Escherichia coli grown under various gas phases was determined by the amount of growth obtained under these conditions. Calcium or strontium was required for activation of haemolysin. The haemolytic reaction was stopped by sodium citrate. The loss of haemolytic activity after incubation with trypsin and chymotrypsin indicated that at least the active group of the haemolytic molecule is protein or a peptide.

\section{INTRODUCTION}

Several studies have shown discordant results about the production and assay of Escherichia coli haemolysins. This paper attempts to clarify the effects of various gas phases on the production of haemolysin and to demonstrate a cation requirement for activation of the haemolysin.

\section{METHODS}

Organism. A haemolysin-producing strain of Escherichia coli type 06 (Iowa Stock Culture, ISC, no. 447), originally obtained from a patient with pyelonephritis, was used. A standard inoculum was obtained as previously described (Snyder \& Koch, 1966).

Measurement of haemolytic activity. Total haemolysin content of the cultures was obtained by two-fold dilution of whole cultures. Filterable haemolysin was determined in the same manner with culture filtrates passed through a Millipore filter $(0.45 \mathrm{~m} \mu$ porosity). The amount of haemolysin/ml. culture or filtrate was determined as previously described (Snyder \& Koch, 1966).

Measurement of growth and $\mathrm{pH}$ value. Turbidometric measurements of growth were obtained with a Spectronic 20 spectrophotometer at a wavelength of $625 \mathrm{~m} \mu$. The $\mathrm{pH}$ value of the culture was determined with a Beckman Zeromatic II pH meter.

Preparation of media. Beef heart for infusion medium (BHI) was prepared from Difco Beef Heart for infusion as described by the manufacturer. When glucose was added to the media, I ml. of a Millipore-filtered solution $20 \%(w / v)$ glucose was added to $100 \mathrm{ml}$. autoclaved media. In media buffered with phosphate, $0 \cdot 23 \mathrm{~g} \cdot \mathrm{K}_{2} \mathrm{HPO}_{4}$ and $0.078 \mathrm{~g}$. $\mathrm{KH}_{2} \mathrm{PO}_{4}$ were added to each $100 \mathrm{ml}$. of medium before sterilization. Alkaline meat-extract broth was prepared as described by Smith (1963).

Incubation of cultures. Anaerobic growth was obtained by using Brewer jars. The jars were flushed with nitrogen three times and filled with hydrogen, a palladium catalyst being used for removal of residual oxygen. Incubation in a $\mathrm{CO}_{2}$ atmosphere 
was done in jars evacuated and filled with $\mathrm{CO}_{2}$ to a concentration of $20 \% \mathrm{CO}_{2}$ and $80 \%$ air $(\mathrm{v} / \mathrm{v})$. Shake cultures were incubated on a rotary shaker at $174 \mathrm{cycles} / \mathrm{min}$ over a one-inch circle. All cultures were incubated at $37^{\circ}$.

\section{RESULTS}

\section{Role of cations in haemolysis}

Filtrates of Escherichia coli cultures grown in BHI medium did not cause haemolysis of sheep erythrocytes unless $\mathrm{Ca}$ was added to the filtrate or to the diluent used for titration of haemolytic activity. This indicated that $\mathrm{Ca}$ was required for activation but not for production of haemolysin. Addition of various amounts of the $\mathrm{Ca}$ showed that a final concentration of $0.005 \mathrm{M}-\mathrm{CaCl}_{2}$ caused maximal activation of the haemolysin (Table I).

To determine whether other cations could substitute for calcium, various concentrations of other cations were added to the $0.15 \mathrm{M}-\mathrm{NaCl}$ used as for assay. Neither barium nor magnesium salts were effective; however, strontium replaced calcium (Table I).

Table I. Effect of various salts on haemolytic activation

\begin{tabular}{lccc} 
Salt & \multicolumn{3}{c}{ Concentration of salts } \\
\cline { 2 - 4 } & \multicolumn{3}{c}{ Haemolytic titre (reciprocal) } \\
$\mathrm{CaCl}_{2}$ & 32 & 32 & 16 \\
$\mathrm{MgSO}_{2}$ & $0.01 \mathrm{M}$ & 0 & 0 \\
$\mathrm{MgCl}_{2}$ & 0 & 0 & 0 \\
$\mathrm{BaCl}_{2}$ & 0 & 0 & 0 \\
$\mathrm{SrCl}_{2}$ & 32 & 16 & 16 \\
$\mathrm{Sr}\left(\mathrm{NO}_{3}\right)_{2}$ & 8 & 16 & 16
\end{tabular}

Table 2. Effect of medium preparation on the calcium requirement for haemolytic activity

\begin{tabular}{lcc}
\multicolumn{2}{c}{ Type of infusion } & Reciprocal of titre \\
\cline { 2 - 3 } Fresh veal $\left(121^{\circ}\right)^{*}$ & 64 & With calcium \\
Fresh beef heart $\left(121^{\circ}\right)$ & 32 & 128 \\
BHI $\left(121^{\circ}\right)$ & 0 & 128 \\
Fresh veal $\left(56^{\circ}\right)$ & 0 & 64 \\
Fresh beef heart $\left(56^{\circ}\right)$ & 0 & 128 \\
BHI $\left(56^{\circ}\right)$ & 0 & 64 \\
\multicolumn{2}{c}{ * Temperature of infusion. }
\end{tabular}

Addition of $\mathrm{CaCl}_{2}$ to culture filtrates caused a precipitate. To determine whether the role of $\mathrm{Ca}$ was in removing an inhibitor, uninoculated medium was precipitated with $\mathrm{CaCl}_{2}$, the precipitate removed by filtration and the medium was dialyzed to remove excess $\mathrm{Ca}$. This medium was then sterilized and inoculated with Escherichia coli. Haemolytic activity was not shown by the filtrates from cultures grown in the dialyzed medium unless calcium was added.

Smith (1963) reported production of haemolysin by Escherichia coli grown in 
alkaline broth prepared by autoclaving I part fresh veal in 2 parts water, I \% proteosepeptone and $0.5 \% \mathrm{NaCl}$ at a $\mathrm{pH} 7 \cdot 6$. A calcium requirement for activation of haemolysin was not reported. To determine whether the method of media preparation or type of medium affected the requirement for calcium, the experiment shown in Table 2 was done. Filtrates of cultures grown in fresh meat infusions prepared by the method of Smith did not require added $\mathrm{Ca}$ for haemolytic activity; however, dehydrated beef heart for infusion (Difco, Detroit, Michigan) prepared in the same manner required Ca. Haemolytic activity could not be obtained with filtrates from alkaline fresh meat infusions prepared at $56^{\circ}$ unless calcium was added. Addition of $\mathrm{Ca}$ to the filtrates from cultures grown in autoclaved infusions increased the haemolytic activity. Autoclaved fresh veal infusion dialyzed before inoculation with $E$. coli did not permit production of activated haemolysin. However, addition of calcium to the filtrate resulted in haemolytic activity.

Attempts to measure quantitatively $\mathrm{Ca}$ in the autoclaved infusions by several methods (Ferro \& Ham, 1957; Clark \& Collip, 1925; Diehl \& Ellingbee, 1956) were unsuccessful. However, small amounts of calcium were detected in the infusions prepared by autoclaving. Calcium was not found in the other media.

Inhibition of haemolytic activity. Since the haemolytic reaction required calcium, the effects of sodium citrate and EDTA on inhibition of the reaction were investigated. Addition of $0 . \mathrm{I} \mathrm{ml}$. of $\mathrm{I} \cdot \mathrm{O} \mathrm{M}$-sodium citrate to $2 \mathrm{ml}$. of an incubating haemolysinerythrocyte mixture stopped the haemolytic reaction. EDTA partially inhibited the haemolysin.

Effect of enzymes on the haemolysin. Samples of haemolysin were incubated with trypsin, chymotrypsin, deoxyribonuclease and ribonuclease. Inactivation of the haemolysin was obtained only with trypsin and chymotrypsin, suggesting that the haemolysin or active portion of the molecule is a protein or peptide.

\section{Effect of gaseous environment on haemolysin production}

Figures I, 2 show the relationships between growth in BHI media, haemolysin production and $\mathrm{pH}$ value in cultures of Escherichia coli type 06 , ISC 447, grown aerobically in a shake culture (Fig. I) and a stationary culture (Fig. 2). Calcium was added to the culture and filtrates for the haemolysin assay. The same measurements were made with cultures grown in $20 \% \mathrm{CO}_{2}(\mathrm{v} / \mathrm{v})$ and air (Fig. 3) and anaerobically (Fig. 4). Filterable and non-filterable haemolysin was produced in all media, however, more haemolysin was produced by organisms grown aerobically than by those grown under the other environmental conditions tested. The production of filterable haemolysin during the logarithmic phase of growth confirms a previous report (Snyder \& Koch, 1966). Both the stationary aerobic culture (Fig. 2) and the cultures grown in $\mathrm{CO}_{2}$ (Fig. 3) showed a diauxic type of growth with an increase in both total and filterable haemolysin during each accelerated growth phase. In all cultures an increase in haemolysin production was associated with a decrease in culture $\mathrm{pH}$ value.

To determine whether better growth of the organisms would result in increased production of haemolysin, glucose and a phosphate buffer was added to BHI medium and the previous experiments were repeated. Increased growth, as indicated by o.D. about 0.7 , was obtained in all cultures except the aerobic shaken culture. Diauxic growth was not obtained in the stationary aerobic culture or the cultures grown in $\mathrm{CO}_{2}$ and haemolysin was produced only during the single logarithmic growth phase 
When compared with cultures grown without glucose there was an increase in total haemolysin produced by cultures grown in stationary aerobic culture as well as in $\mathrm{CO}_{2}$ and anaerobically. However, there was no significant increase in the yield of filterable haemolysin.
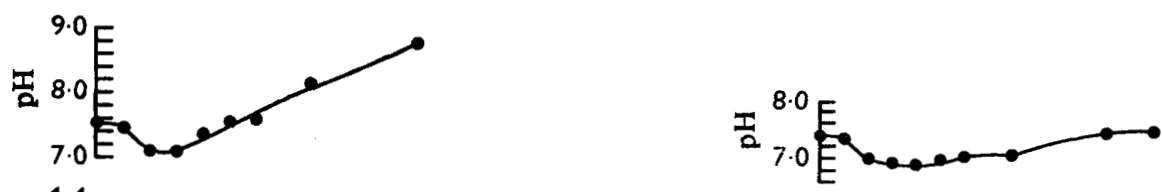

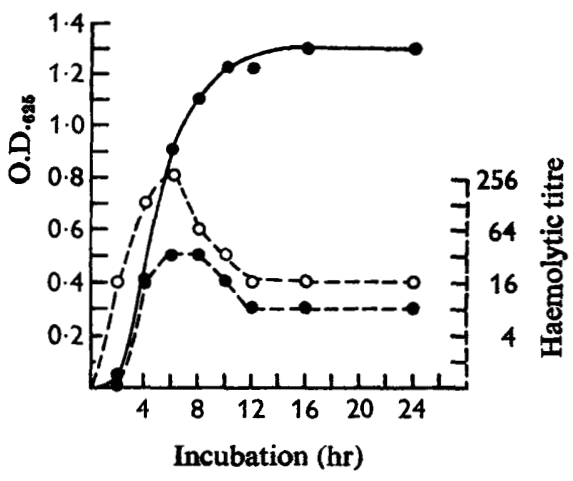

Fig. I

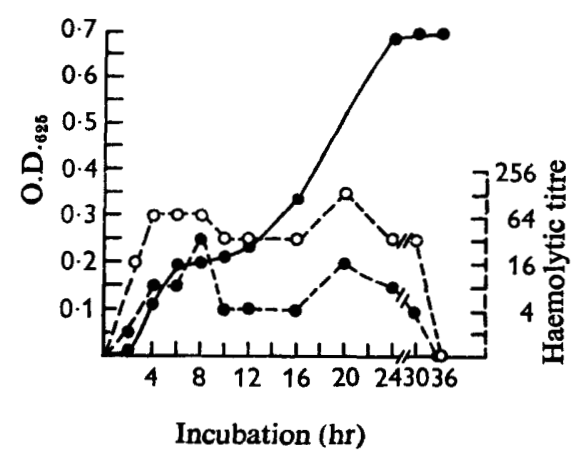

Fig. 2
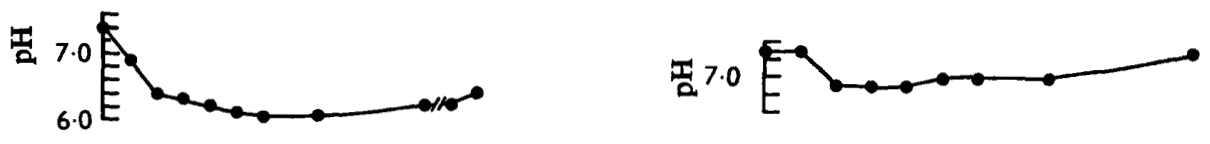

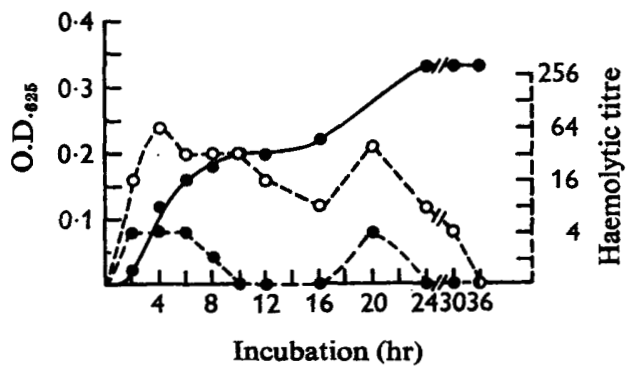

Fig. 3

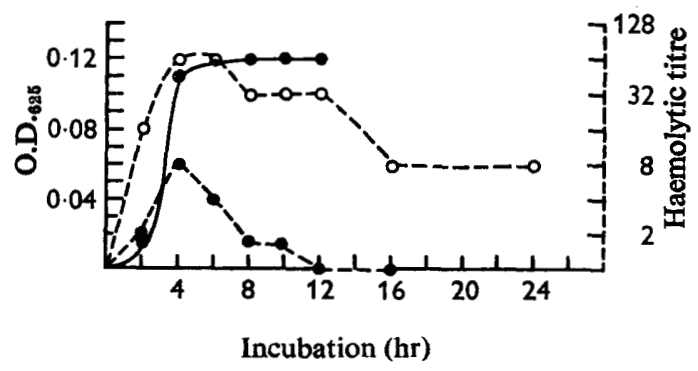

Fig. 4

Fig. I. Effect of agitation on haemolysin production in medium without added carbohydrate. - Growth, O - O total haemolysin in culture, - - - filterable haemolysin.

Fig. 2. Effect of stationary growth on haemolysin production in medium without added carbohydrate. - $\bullet$ Growth, $O_{-}-O$ total haemolysin in culture, $\bullet-\bullet$ filterable haemolysin.

Fig. 3. Effect of $\mathrm{CO}_{2}$ on haemolysin production in medium without added carbohydrate. - Growth, $\mathrm{O}$ - - O total haemolysin in culture, -. - filterable haemolysin.

Fig. 4. Effect of anaerobiosis on haemolysin production in medium without added carbohydrate. - Growth, $\bigcirc--O$ total haemolysin in culture, - - $\bullet$ filterable haemolysin. 


\section{DISCUSSION}

The data presented show that production of Escherichia coli haemolysin was obtained during growth in various gas phases. More haemolysin was produced aerobically either in shaken or stationary cultures than in cultures grown in $\mathrm{CO}_{2}$ or anaerobically. However, since better bacterial growth was obtained in cultures growing aerobically, glucose and phosphate were added to the cultures to improve growth. These additions increased bacterial growth especially in the cultures grown in $\mathrm{CO}_{2}$ and anaerobically and increased the production of haemolysin. No significant increase in filterable haemolysin was obtained. Tomic-Karovic (1955) found more haemolysin was produced when $E$. coli was grown on blood agar in an atmosphere of $\mathrm{CO}_{2}$ than in air and that the least haemolysin was produced in an anaerobic atmosphere. Ishii (I960) found greater production of haemolysin under $\mathrm{CO}_{2}$ than in air. Lovell \& Rees (I960) reported less haemolytic activity in cultures grown in $\mathrm{CO}_{2}$ or hydrogen than those grown aerobically. Widholm (1953) found that various mixtures of oxygen and nitrogen did not affect haemolysin production. The differences in the reports most likely can be attributed to differences in time of sampling the culture filtrates. Cultures growing under more ideal environmental conditions will produce haemolysin at a faster rate than other cultures. In all cases, production of haemolysin is associated with a decrease in $\mathrm{pH}$ value and with growth of the organisms.

Our experiments on the role of cations in haemolysis show that cations are responsible for activation of the haemolysin and are not responsible for production. Bamforth \& Dudgeon (1952) reported that calcium was required for haemolytic activity and that barium and strontium could be substituted for calcium; we were not able to show haemolytic activity with barium. Other workers (Lovell \& Rees, 1960; Smith, 1963) did not report a requirement for calcium. However, these workers used an alkaline meat extract broth. Our studies with the alkaline meat extract show (I) that some calcium is present in the alkaline meat extract, and (2) that haemolysin cannot be demonstrated in cultures of Escherichia coli grown in dialyzed broth unless calcium is added.

This investigation was supported by U.S. Public Health Service research grant AI-05266 from the National Institute of Allergy and Infectious Diseases.

\section{REFERENCES}

Bamforth, J. \& Dudgeon, J. A. (1952). Haemolytic activity of Bacterium coli. J. Path. Bact. 64, 751. Clark, E. P. \& ColliP, J. B. (1925). A study of the Tisdall method for the determination of blood serum calcium with a suggested modification. J. biol. Chem. 63, 46I.

DieHL, H. \& Ellingbee, J. L. (1956). Indicator for the titration of calcium in the presence of magnesium with disodium dihydrogen ethylenediamine tetraacetate. Analyt. Chem. $28,822$.

Ferro, P. V. \& HAM, A. B. (1957). A simple spectrophotometric method for the determination of calcium. Am. J. clin. Path. 28, 208.

IsHII, F. (1960). Studies on the hemolytic property of Escherichia coli. Jap. J. Microbiol. 4, 203.

Lovell, R. \& ReEs, T. A. (1960). A filterable hemolysin from Escherichia coli. Nature, Lond. 188, 755.

Smith, H. W. (1963). The haemolysins of Escherichia coli. J. Path. Bact. 85, 197.

SNYDER, I. S. \& Koch, N. A. (1966). Production and characteristics of hemolysins of Escherichia coli. J. Bact. 91, 763 .

Tomic-Karovic, K. (1955). Haemolytische Escherichiae and Proteae. Zentralbl. Abt. I, Orig. I62, 37.

Widholm, O. (1953). Studies on Escherichia coli hemolysins and antihemolysins. Ann. Med. Exp. Biol. Fenn. 31, Suppl. I-8, I. 